\title{
USO AGRÍCOLA DO TERRITÓRIO E TRABALHO CIENTÍFICO PARA O CAMPO MODERNO NO BRASIL*
}

\author{
Francisco C. Nascimento Junior**
}

Resumo: A introdução de novas bases técnicas de produção no campo tornou o trabalho científico uma atividade central para a determinação das possibilidades de uso agrícola do território brasileiro no período atual. Neste breve texto analisaremos o processo de constituição do círculo de cooperação de pesquisa agrícola no Brasil, destacando, especialmente, o poder do Estado e do mercado no comando das pesquisas biotecnológicas dirigidas ao campo moderno. Por fim, num esforço de síntese, buscaremos reconhecer os paradoxos e contradições produzidos pela forma corporativa de realização do processo de modernização da atividade agrícola no território brasileiro.

Palavras-chave: uso do território, círculo de cooperação, agricultura científica, contradição, soja.

\section{AGRICULTURAL USE OF THE TERRITORY AND SCIENTIFIC WORK FOR THE MODERN FIELD IN BRAZIL}

\begin{abstract}
The introduction of new technologies of agricultural production has defined the scientific work as a central activity in the determination the possibilities of the agricultural use of the Brazilian territory in the current historical period. In this paper we analyze the process of constitution of the cooperation circle of agricultural research in Brazil, highlighting, especially, the power of the State and the market in the command of biotechnological research to the modern field. Finally, in a effort of synthesis, we seek to recognize the paradoxes and contradictions that involve the way corporate of realization of the modernization of agriculture in the Brazilian territory.
\end{abstract}

Keywords: use of the territory, cooperation circle, scientific agriculture, contradiction, soybeans.

\section{Introdução}

A emergência do período técnico-científico-informacional no Brasil trouxe consigo as condições para que os agentes hegemônicos da economia pudessem promover uma verdadeira reorganização da produção agrícola no território nacional. A introdução de inovações técnicas no campo relativizou a importância dos fatores naturais, permitindo a ampliação da produtividade territorial daqueles lugares que já realizavam uma agricultura comercial, além de possibilitar que lugares considerados a princípio inaptos a realização de uma agricultura capitalista fossem, rapidamente, incorporados aos modernos circuitos produtivos do agronegócio. Todavia, deve-se salientar que este processo de modernização da agricultura nacional se deu de maneira seletiva, isto é, privilegiando, sobretudo aqueles lugares mais funcionais às estratégias de acumulação das grandes empresas do agronegócio, e valorizando, sobretudo aqueles produtos mais requeridos pelo mercado internacional de commodities.

\footnotetext{
* Este texto apresenta um resumo das principais ideias que desenvolvemos em nossa pesquisa de mestrado, intitulada $A$ constituição do círculo de cooperação de pesquisa agrícola no Brasil: nova face do uso corporativo do território brasileiro no período técnico-científico-informacional, defendida em 2007, no Programa de Pós-graduação em Geografia da Unesp, em Rio Claro, sob orientação da Prof ${ }^{a}$ Dr $^{a}$ Samira Peduti Kahil.

** Doutorando do Programa de Pós-graduação em Geografia da Unesp, Rio Claro. Pesquisa financiada pelo CNPq.
} 
A busca dos agentes hegemônicos da economia pela construção de um meio geográfico instrumental no campo se deu como estratégia para possibilitar a reprodução ampliada do capital no território brasileiro. A difusão seletiva dessa agricultura científica no Brasil foi bem sucedida porque resultou de um trabalho intelectual que concebeu engenhosamente a produção agrícola em pontos específicos do território (SANTOS; SILVEIRA, 2001).

Num primeiro momento coube essencialmente ao Estado criar o círculo de cooperação de pesquisa científica necessário à expansão da moderna agricultura capitalista no território nacional, de modo a reafirmar ainda a função brasileira na divisão internacional do trabalho, como país agroexportador. Entretanto, ao passo que a atividade agrícola moderna consolidou-se em determinadas regiões do país, grandes empresas de biotecnologia tornaram-se cada vez mais interessadas em exercer controle sobre pesquisa tecnológica voltada ao campo moderno. $\mathrm{Na}$ medida em que o funcionamento e a competitividade dos espaços agrícolas modernos tornaram-se crescentemente dependente dos avanços técnico-científicos alcançados pela pesquisa agrícola, o trabalho científico dirigido ao campo tornou-se um novo e importante negócio das grandes corporações no território brasileiro.

\section{A centralidade do Estado brasileiro na cooperação científica para a reorganização territorial da produção agrícola moderna}

Durante 0 século $X X \quad 0$ Estado brasileiro se firmou como o principal agente promotor do processo de modernização da agricultura nacional, algo que se deu através da criação de políticas específicas para o aprimoramento seletivo da agricultura comercial no país. Especialmente no que diz respeito aos esforços para a renovação das bases técnicas da produção no campo, suas ações foram fundamentais, sendo mesmo responsáveis por conduzir a formação de um extenso círculo de cooperação de pesquisa agrícola. Dispondo de serviços técnicos, escolas de agronomia e centros de pesquisa que precederam, acompanharam, ou sucederam as ações das empresas no território nacional, o poder público mostrouse sempre ativo no apoio técnico e científico para a constituição de regiões especializadas na moderna produção agrícola (SANTOS; SILVEIRA, 2001).

De maneira geral, as políticas de Estado tiveram a finalidade de tornar viável a agricultura capitalista no território brasileiro. As atividades de órgãos e instituições públicas de pesquisa no país estiveram orientadas pela ideia de tornar alguns subespaços nacionais funcionais aos modernos e internacionalizados circuitos produtivos do agronegócio. A concentração dos esforços de pesquisa científica no desenvolvimento de determinadas produções agrícolas teve 0 intuito de tornar tecnicamente eficiente e economicamente rentável aqueles gêneros agrícolas mais requeridos pela agroindústria, atendendo simultaneamente, as exigências do grande capital por maior eficiência do trabalho e maior racionalidade da produção no campo. É neste sentido, que as ações estatais para prover o país de uma estrutura territorial de pesquisa agrícola, também colaboraram com as estratégias de uso corporativo do território brasileiro pelas grandes empresas atuantes no agronegócio nacional e internacional. 
A criação da Embrapa (Empresa Brasileira de Pesquisa Agropecuária) pelo governo federal, em 1973, se constituiu num dos principais instrumentos do projeto de modernização do campo brasileiro. Concentrando suas ações na criação e difusão de tecnologias com vistas ao aprimoramento de alguns circuitos produtivos agrícolas, a Embrapa se consolidou rapidamente como o principal agente do círculo de cooperação de pesquisa científica, especialmente, aquele orientado ao aprimoramento da produção de commodities, como o caso da soja.

A centralidade exercida pela Embrapa na cooperação técnica e científica para a modernização agrícola esteve associada a sua função de coordenação do Sistema Nacional de Pesquisa Agropecuária (SNPA) - arranjo institucional e organizacional que articula, desde os anos 1970, as dezenas de unidades de pesquisa da Embrapa às universidades, fundações e empresas de pesquisa públicas e privadas localizadas nas diversas regiões do país. A solidariedade organizacional e institucional (SANTOS, 2002; CASTILLO; MENDES; ANDRADE, 1997) construída a partir desse sistema normativo, assenta-se sob o princípio da convergência e articulação do trabalho científico realizado nas diversas áreas do conhecimento, de modo a tornar mais eficaz a produção agropecuária, e viabilizar a realização dessa produção em pontos estratégicos do território nacional.

Ao longo das primeiras décadas da marcha modernizadora da agricultura nacional coube especialmente a Embrapa assumir a função de elaborar e conduzir as iniciativas internas de pesquisa para a criação de novas tecnologias de produção, adaptadas a cada região do país, de modo a possibilitar a efetivação dos projetos de reorganização produtiva do território, formulados pelo governo federal. As ações da empresa pública alinharam-se aos Planos Nacionais de Desenvolvimento (PND) e aos programas regionais de desenvolvimento agropecuário, tais como o Polocentro (Programa de Desenvolvimento dos Cerrados), o Polonordeste (Programa de Desenvolvimento de Áreas Integradas do Nordeste) e o Prodecer (Programa de Cooperação NipoBrasileira de Desenvolvimento dos Cerrados) (SHIKI; GRAZIANO DA SILVA; ORTEGA, 1998; DELGADO, 1985). Pode-se dizer que os programas de desenvolvimento de pesquisas visando um novo uso agrícola do território brasileiro, definiam-se já naquele momento, como projetos técnicos e políticos simultaneamente, haja vista a produção induzida de tecnologias constituir-se num fator fundamental para a concretização das políticas oficiais de uso econômico das áreas do território nacional consideradas periféricas.

As atividades da empresa pública permitiram, nas últimas décadas, a reorganização do espaço agrícola brasileiro juntamente com uma profunda, mas seletiva, racionalização da produção no campo. Através da produção de uma verdadeira tecnociência a empresa pública serviu de ferramenta para a otimização, especialmente das atividades agroexportadoras no Brasil, viabilizando direta ou indiretamente as estratégias territoriais, das grandes corporações que comandam os circuitos hegemônicos do agronegócio no país. Deste modo, se o Estado propiciou as condições básicas para o desenvolvimento capitalista na agricultura, promovendo a constituição de um meio geográfico racional no campo, o próprio poder público tornou-se também responsável por acentuar as desigualdades entre os homens e os lugares no território nacional (GRAZIANO DA SILVA, 1982). 
A incorporação de determinados "lugares de reserva", inicialmente do CentroOeste e posteriormente do Norte e do Nordeste do país aos circuitos produtivos hegemônicos, já figurava nos programas federais de modernização e integração econômica do território. A política de "ocupação periférica do território" (SANTOS; SILVEIRA, 2001) e a criação, no Brasil central, de uma vasta região especializada na produção agropecuária, que se constituiria num verdadeiro "celeiro de alimentos do mundo", centralizava o discurso do governo militar na década de 1970. O Estado, enquanto instituição normatizadora, reguladora da vida nacional (em escala nacional, estadual e municipal), através de políticas oficiais e através da ação de instituições públicas, exerceu um importante papel na definição de uma nova divisão territorial do trabalho do país, criando ainda, o que, juntamente com Castillo, Mendes e Andrade (1997), podemos chamar de solidariedade institucional.

A fundação do SNPA e o desenvolvimento dos planos de integração nacional que equiparam o território brasileiro com sistemas de informação e de transporte tornaram o território mais fluido, o que possibilitou o desenvolvimento de redes nacionais de pesquisa. A maior fluidez do território viabilizou a articulação das atividades de desenvolvimento de pesquisas técnico-científicas entre universidades, fundações, centros de pesquisas e empresas instalados em diferentes pontos do território nacional, formando assim uma extensa e complexa organização territorial do trabalho científico, coordenada pela Embrapa.

A partir de uma extensa estrutura territorial de pesquisa e da produção de uma ciência utilitária, baseada tanto na introdução de tecnologias estrangeiras no país, como na criação de técnicas próprias, novas possibilidades de uso do território brasileiro foram oferecidas aos agentes hegemônicos da economia agrícola, e estes ampliaram suas ações no território brasileiro estimulados, sobretudo pelas possibilidades de ampliação de ganhos econômicos oferecidas pelas novas bases técnicas de produção introduzidas seletivamente no campo brasileiro.

Em nossa pesquisa de mestrado (NASCIMENTO JR., 2007) pudemos constatar que especialmente para o aprimoramento tecnológico da produção de soja no território brasileiro a Embrapa mobilizou (e ainda mobiliza) um grande número de instituições no país e também no exterior. O processo de concepção dos sistemas técnicos aplicados à agricultura científica, apesar de ser realizado com o objetivo de contemplar uma determinada região é, em muitos casos, fruto de um trabalho de pesquisa coordenado e executado solidariamente por instituições que se encontram, não raramente, distantes da região de aplicação dos inventos técnicos. Os espaços agrícolas modernos, funcionais aos circuitos produtivos hegemônicos, se constituem em pontos articulados às atividades desenvolvidas em inúmeras outras localidades que integram o círculo de cooperação da agricultura científica. Esta divisão técnica e territorial do trabalho acaba por evidenciar mesmo, a significativa ampliação da área de produção da agricultura moderna, e consequentemente a dependência destas regiões em relação aos lugares (e aos agentes) que comandam a produção científica voltada ao campo moderno.

A partir da centralização dos esforços para a viabilização e o aprimoramento 
territorial da agricultura, o Estado brasileiro passou a deter um controle parcial das bases técnicas da moderna produção agrícola nacional. Desde os anos 1970, o Brasil construiu uma relativa autonomia na criação de algumas inovações biotecnológicas. Um claro exemplo do protagonismo e da supremacia da Embrapa no comando científico da moderna produção agrícola foi a participação da empresa pública no "mercado nacional de sementes de soja" na década de 1990. Em 1998, 75\% da área cultivada com soja em todo o território brasileiro fazia uso das inovações biotecnológicas (cultivares) desenvolvidas pela empresa (EMBRAPA, 2006a).

\section{A regulação do território pelo mercado e a mercantilização da pesquisa agrícola no Brasil}

Os anos 1990 vão representar uma nova fase na dinâmica, organização e regulação da atividade de pesquisa científica, voltada a moderna produção agrícola no Brasil. A intensificação do processo de globalização caminhou juntamente com o predomínio da lógica do mercado sobre o desenvolvimento das mais diversas esferas da vida da nação (a criação de normas, a estrutura das profissões, o desenvolvimento das pesquisas, a instalação de infraestrutura no território etc.). Como nos lembram Milton Santos e Maria Laura Silveira (2001), tal processo se fez através de uma regulação política do território e particularmente de uma regulação do território exercida, diretamente, pelo próprio mercado (isto é, pelas empresas) e ritmada pelo imperativo da competitividade.

A ideologia neoliberal que fundamenta as ações políticas no território brasileiro vem sendo responsável por redefinir o papel do Estado e do mercado (as empresas) na organização e regulação das atividades econômicas no país. No que diz respeito ao desenvolvimento das pesquisas tecnológicas para a agricultura, importantes mudanças se sucederam, demonstrando o dinamismo da constituição do círculo de cooperação de pesquisa agrícola brasileiro e evidenciando as novas formas de regulação do território, próprias ao atual período técnico-científico-informacional.

Como vimos, durante as duas primeiras décadas do projeto de modernização da agricultura, o Estado brasileiro conduziu e financiou a maior parte dos esforços para o aprimoramento técnico da produção agrícola hegemônica. Contudo, aquela presença predominante do Estado nas pesquisas agrícolas aplicadas (o desenvolvimento tecnológico) vem sendo, gradativamente, alterada a favor de uma maior participação das empresas privadas, sobretudo no desenvolvimento das pesquisas em biotecnologia no Brasil. Trata-se de uma nova ordem, que se difunde e redefine $o$ papel do Estado e das empresas na produção da tecnociência no atual período de desenvolvimento do capitalismo (KARPIK, 1972; SANTOS, 1983).

\section{Os avanços técnico-científicos} obtidos, sobretudo pelas instituições públicas de pesquisa, possibilitaram a expansão e a consolidação da agricultura científica em algumas regiões do território nacional, fornecendo assim as condições de territorialização e/ou de consolidação de um mercado para que as empresas privadas, somente agora, viessem participar, com maior intensidade, das atividades de pesquisa de inovação tecnológica. Tal participação só foi vantajosamente possível, 
agora, depois que o Estado assumiu os "riscos" de tais investimentos, que eram de monta e de longo prazo, criando as tecnologias necessárias para a expansão territorial da moderna atividade agrícola e a integração passiva de determinadas regiões brasileiras aos circuitos produtivos globalizados.

$\mathrm{Na}$ medida em que algumas atividades agrícolas hegemônicas, como a produção de soja, tornam-se cada vez mais exigentes da racionalidade técnica e instrumental para a realização competitiva da produção, estabelece-se um consumo produtivo naqueles subespaços de desenvolvimento da agricultura científica (ELIAS, 2003) e, concomitantemente, aprofunda-se a dependência destes subespaços em relação àqueles centros de desenvolvimento de novas tecnologias. Tal dependência dá-se tanto para fins de viabilização da produção numa dada região, como também, relaciona-se à necessidade intrínseca à agricultura capitalista de buscar constantemente o aumento da produtividade espacial, ampliação dos rendimentos com a lavoura e a redução dos custos. Ao tornar-se o insumo fundamental para a realização da agricultura moderna o uso da tecnociência no campo cria também novas oportunidades de negócio para as empresas privadas.

Deste modo a iniciativa privada, nos últimos tempos, passa também a expandir seletivamente suas atividades no país, aumentando, sobretudo seus investimentos em pesquisa e na inovação biotecnológica. É em forma de "pontos" e "manchas" que se configuram as áreas alvo das estratégias de ação desses agentes no território brasileiro. Configurando-se de modo descontínuo no território as regiões especializadas na produção de commodities constituem-se nas áreas privilegiadas pelas empresas privadas para a criação de novas tecnologias. Tais agentes operam, desse modo, uma "segmentação vertical do território nacional" (SANTOS, 1989), haja vista seus interesses não integrarem o território como um todo e de forma contígua, mas sim, incorporarem pedaços do território nacional às suas estratégias territoriais de acumulação. Neste sentido, pode-se dizer que essas estratégias de ação das empresas que usam o território como mercado, promovem também uma verdadeira fragmentação do território nacional (SANTOS; SILVEIRA, 2001; SANTOS, 1989).

$\begin{array}{ccc}\text { Além da permanência e } & \text { o } \\ \text { fortalecimento de alguns programas de }\end{array}$ pesquisa públicos e privados já existentes no Brasil (tais como os programas da Embrapa e da Coodetec [Cooperativa de Desenvolvimento Tecnológico do Paraná]), a partir da década de 1990 outras instituições de pesquisa passaram a atuar na cooperação científica para a produção de soja, no qual se destacam as nacionais, Fundação MT (Fundação de Apoio à pesquisa Agropecuária do Mato Grosso) e TMG (Tropical Melhoramento Genético), e as multinacionais Monsanto/Monsoy, Pioneer, Syngenta, Milênia e Nidera; estas cinco últimas responsáveis pelo claro processo de transnacionalização da pesquisa biotecnológica no país.

Especialmente na segunda metade dos anos 1990, as atividades de pesquisa das empresas privadas para a produção de soja foram, sensivelmente, estimuladas e viabilizadas a partir da criação de um sistema de normas que regulamentaram as atividades de criação e comercialização de sementes e cultivares no Brasil. Em que pese a pressão política exercida por associações de classe, 
grandes empresas de pesquisa e grandes produtores, quando da elaboração do marco regulatório, a aprovação da Lei de Proteção de Cultivares em 1997 (Lei n. 9.456, de 25 de abril de 1997) pelo governo federal, forneceu a "segurança" necessária para que as empresas privadas viessem atuar com maior pujança nas atividades de pesquisa para a moderna agricultura no Brasil. Tal regulamentação obrigava o pagamento de royalties pela comercialização (difusão) e uso dos cultivares gerados pelas empresas, o que assegurava o retorno econômico dos investimentos em pesquisa realizados por aqueles agentes. Neste sentido, pode-se dizer que o Estado, através da função reguladora que exerce, tornou-se imprescindível para a concretização das estratégias privadas de uso corporativo do território.

Além da criação da Lei de Proteção de Cultivares, outras normas contribuíram para viabilizar (e dar segurança financeira) à expansão das ações das corporações na promoção das pesquisas biotecnológicas no país. A aprovação, em 1995, da Lei de Biossegurança (Lei n. 8.974/95) constituiu um outro importante marco para a dinamização das pesquisas com Organismos Geneticamente Modificados (OGM), os denominados transgênicos. Contudo, o passo definitivo para a regulamentação da produção de soja transgênica no território brasileiro deu-se, em 2005, com a promulgação da Lei n. 11.105, que legalizou tanto a produção como a comercialização de soja transgênica em nosso país. ${ }^{1}$ Também sob forte pressão

\footnotetext{
1 Já em 2003, por Medida Provisória, o governo brasileiro havia liberado o plantio de soja transgênica no país, até então proibida. Sob forte pressão dos grandes produtores e transgredindo o princípio da precaução, que restringia a legalização desse tipo de produção em face da inexistência de um conhecimento mais apurado sobre as consequências que os organismos geneticamente
}

dos grandes produtores e das empresas detentoras dessa tecnologia, pressão principalmente exercida por algumas corporações como a multinacional Monsanto, o governo brasileiro regulamentou o uso de transgênicos, até então utilizados ilegalmente, mas já bastante difundido em determinadas regiões do país. ${ }^{2}$ Por sua vez, com a regulamentação da produção dos transgênicos difundiu-se, amplamente no território brasileiro, um sistema técnico de produção, que garante ganhos econômicos ao produtor já que reduz a quantidade de insumos químicos empregados no manejo da lavoura (BOUÇAS, 2006a).

Já na safra 2006/2007, estimou-se, por exemplo, que a produção de soja transgênica representasse entre 50\% e 60\% da área total cultivada no país (BOUÇAS, 2006b). Nos últimos anos, a produção de soja transgênica tende a se tornar predominante no território brasileiro, substituindo, rapidamente, a chamada produção convencional. Assim é que a criação de normas constituiu-se num importante mecanismo de viabilização e favorecimento das estratégias territoriais de algumas empresas no país. Através da lei de propriedade intelectual (patente), que concede a exclusividade sobre a exploração comercial da tecnologia a seu inventor, institui-se também uma nova forma de controle e regulação sobre a atividade

modificados poderiam trazer ao ser humano e ao sistema ecológico - de maneira deliberada, à revelia de um debate público que há anos se realizava a esse respeito, o governo cedeu claramente aos interesses econômicos que envolvem o cultivo dos produtos transgênicos no país.

2 O Rio Grande do Sul era o estado com o maior volume de produção de soja transgênica no Brasil. Estima-se que, antes da liberação, $80 \%$ da produção de soja naquele estado já usasse esse tipo de tecnologia. 
produtiva e sobre os lugares da produção agrícola moderna.

De forma clara, esses grandes empreendedores vêm usando o território nacional a seu talante selecionando, no mais das vezes, as regiões e a produções agrícolas de maior relevância econômica. Com estratégias territoriais seletivas e vultosos investimentos em grandes programas de pesquisa, essas grandes corporações integraram-se ao círculo de cooperação de pesquisa agrícola nacional, tornando-se mesmo, alguns dos principais agentes promotores das inovações técnico-científicas que se difundem pelo moderno campo Brasileiro.

Entretanto, a mercantilização da pesquisa agrícola e a construção de um aparato normativo responsável por beneficiar as ações das grandes empresas privadas constitui-se, pode-se assim dizer, numa situação a princípio pouco vantajosa para países subdesenvolvidos, como o Brasil. Isto porque a maior capacidade dos países ricos de realizar vultosos investimentos no desenvolvimento de pesquisas científicas permite aos mesmos comandar o processo geral de inovação tecnológica e, ao mesmo tempo, impor uma divisão internacional do trabalho a seu favor. Na medida em que a produção da pesquisa de "alta tecnologia" se caracteriza como restrita a algumas empresas e alguns países desenvolvidos, as nações periféricas têm aprofundada sua dependência tecnológica e o desenvolvimento desigual e combinado, inerente ao modo de produção capitalista, tende a se agravar, visto que mesmo a pesquisa tecnológica voltada a agropecuária apresenta-se também bastante concentrada nos países desenvolvidos. Juntos, União Europeia $(33,87 \%)$, Estados Unidos $(32,41 \%)$ e Japão
$(7,44 \%)$ reuniam, em 1999, quase $75 \%$ da produção científica para a agropecuária no mundo (CONTINI; REIFSHNEIDER; SAVIDAN, 2004).

\section{Hierarquia territorial e controle corporativo do trabalho tecno-científico}

Vimos que o círculo de cooperação de pesquisa agrícola para a produção de soja no Brasil está, atualmente, amparado por uma ampla e complexa estrutura territorial de pesquisa constituída ao longo de décadas inicialmente pelo "empreendedorismo modernizador" do Estado brasileiro (governos federal e estadual) e, mais recentemente, reforçada pelas espessas estratégias territoriais promovidas por empresas privadas de pesquisa, nacionais e estrangeiras. Todavia, as redes de pesquisa criadas de forma corporativa revelam também a existência de papéis e funções distintas exercidas entre os lugares que a constituem. Trata-se de uma divisão territorial do trabalho científico associada ao estabelecimento de um comando centralizado das atividades, dado a partir de lugares e empresas que coordenam cada uma das fases do trabalho de pesquisa e desenvolvimento tecnológico, realizados em lugares distintos do território brasileiro.

A medida que se pode hoje constatar que os programas de pesquisa responsáveis por causar maior impacto técnico na produção e na produtividade de soja estão sob a liderança e comando de algumas poucas empresas, podemos de maneira geral dizer que a elas se atribui o papel de controle sobre o desenvolvimento tecnológico para a produção de soja, o que, de outro lado, implica também o controle sobre as próprias possibilidades de uso agrícola do território 
brasileiro. Em 2005, apenas quatro empresas - Embrapa (34\%), Coodetec (20\%), Monsanto (18\%) e Fundação MT (17\%) (EXAME, 2005) detinham 91\% do mercado nacional de cultivares de soja, o que constitui uma forma de oligopolização do território.

$$
\text { Como pudemos verificar }
$$

(NASCIMENTO, 2007) as principais redes de pesquisa arquitetadas para o aprimoramento da produção de soja no Brasil não estão amparadas apenas nas atividades desenvolvidas por aquelas grandes empresas que compõem o círculo de cooperação de pesquisa agrícola. Integradas às redes corporativas de pesquisa elaboradas e conduzidas pelas grandes empresas (Embrapa, Coodetec, Monsanto e Fundação MT) somam-se, com frequência, a participação de outras instituições. Cumprindo atividades científicas que integram importantes fases da execução desses grandes programas de pesquisa, universidades, fundações e instituições de pesquisa públicas apóiam, auxiliam e viabilizam, tecnicamente e regionalmente, o processo de inovação tecnológica para a produção de soja no território brasileiro. Entretanto, como agentes articulados a uma rede de pesquisa maior, cuja elaboração e coordenação desses programas fogem do seu controle, estas instituições caracterizam-se por ocuparem uma posição subordinada dentro da hierarquia territorial do trabalho científico.

Enquanto as grandes empresas de pesquisa (Embrapa, Coodetec, Monsanto e Fundação MT) desempenham o papel de elaboração, coordenação e comando dos principais programas de pesquisa em biotecnologia no país, universidades, fundações e demais instituições de pesquisa públicas ocupam um papel "secundário", porém não menos importante nas redes corporativas de pesquisa para a soja. Com um know-how historicamente adquirido e conhecimentos regionalmente produzidos, a presença das universidades e instituições estaduais de pesquisa torna-se, frequentemente necessária ao próprio sucesso dos programas de investigação, elaborados pelas grandes empresas privadas, com a finalidade de aprimorar especialmente a produção de soja que é muito exigente da criação engenhosa de sistemas técnicos para seu desenvolvimento eficiente em regiões diversas do país. A partir, então, do atual feitio do trabalho técnico-científico que trata de conceber e planejar a realização da moderna produção agrícola, universidades e institutos federais e estaduais de pesquisa agrícola tornam-se importantes recursos territoriais para que as grandes empresas de pesquisa, a partir do estabelecimento de convênios e parcerias, possam promover seus projetos de inovação técnica para a produção de soja e assim viabilizar suas estratégias de mercado no Brasil.

Através desta forma de constituição das redes de pesquisa, podemos dizer que fundem-se e confundem-se, o público e o privado, o Estado e o mercado para efeito da concretização de programas de pesquisa verdadeiramente privados tanto em sua natureza ideológica como nos benefícios econômicos angariados com as invenções técnicas alcançadas. É neste sentido que podemos também dizer que toda a sociedade brasileira foi (e ainda é) convocada a unir esforços e despender recursos para a conquista do progresso técnico e a "competitividade" da produção de soja no Brasil, portanto, convocada a colaborar para o benefício particular de apenas alguns agentes no país. 


\section{A solidariedade construída e as territoriais produzidas}

organizacional desarticulações

A construção de solidariedades organizacionais que buscam instituir uma racionalidade ao território produz nexos, essencialmente funcionais entre os lugares e as instituições. O estabelecimento de redes que buscam cumprir determinadas finalidades permite uma eficiência produtiva de parcelas do território nacional e um uso corporativo do território pelos agentes hegemônicos da economia e da política.

Conforme Santos e Silveira (2001), a prosperidade dos agentes promotores das solidariedades organizacionais é dada, em muitos casos, à custa do bem-estar da sociedade nacional, visto que a construção da racionalidade técnica do território nacional não se faz necessariamente em benefício da maior parte da população. Neste sentido, a solidariedade organizacional estabelecida pode, também, produzir desarticulações internas ao território nacional, na medida em que se constituem nexos espaciais essencialmente funcionais, presididos por interesses mercantis e responsáveis por um uso privilegiado dos recursos do território. É sob a invenção da necessidade de viabilização do território aos circuitos produtivos hegemônicos que se organiza e se instrumentaliza o território nacional, promovendo-se, racionalmente, a sua fragmentação.

A produção de uma atividade científica utilitária, de caráter mercadológico realizada por empresas, universidades e outras instituições públicas e privadas de pesquisa revela, igualmente, a construção de solidariedades organizacionais que, ao proporcionar um uso seletivo do território por alguns circuitos produtivos do agronegócio contribui, concomitantemente, para o rompimento da coesão social do país. Este processo se dá em decorrência da internalização de um projeto de modernização das atividades e do próprio território regida por interesses corporativos, muito ligados aos projetos e estratégias de mercado das grandes empresas que (do exterior) comandam as atividades produtivas hegemônicas do país.

A constituição do círculo de cooperação de pesquisa agrícola no Brasil vem, igualmente, evidenciar o caráter contraditório das solidariedades organizacionais e institucionais construídas no território nacional. O aumento vertiginoso da capacidade de produção agrícola brasileira, resultado dos progressos técnico-científicos promovidos, sobretudo, por empresas, institutos e universidades públicas nacionais ao longo das últimas décadas, se defronta com a escassez de alimentos que ainda aflige considerável parcela da população brasileira, evidenciando assim a lógica perversa presente neste projeto hegemônico de instrumentalização do território brasileiro que se perpetua e se aprimora ao longo de todo o processo de formação do país.

Esse paradoxo de abundância e de escassez de alimentos no território brasileiro pode ser visto pelo aumento constante de pessoas famintas no país, dado em ritmo e intensidade semelhantes àqueles índices alcançados pelo aumento da produção de grãos, índice para o qual a produção soja, contabiliza cerca de $50 \%$ das safras. Enquanto, entre 1990 e 2004, a safra de grãos mais que dobrou, saltando de cerca de 57 milhões de toneladas para algo próximo de 126 milhões de toneladas, o número de pessoas com fome no país aumentou em 
proporção semelhante, passando de cerca de 30 milhões de pessoas famintas em 1990 para 56 milhões em 2004 (CARNEIRO; PEREIRA, 2005). Diferentemente do fenômeno da fome em outros países, cuja baixa densidade técnico-científica do meio geográfico inviabiliza a realização da produção de alimentos em escala, o Brasil atende e até supera os parâmetros internacionais que estipulam que um país deva produzir 500 quilos de grãos por habitante/ano para poder suprir as necessidades nutricionais de seus habitantes (EMBRAPA, 2004).

Diante da crescente produção de grãos no Brasil tudo nos leva a crer que a escassez de alimentos em nosso país é uma escassez produzida intencionalmente, e o problema da fome que atinge milhões de brasileiros é um problema político e ético - já que as possibilidades técnico-científicas estão dadas, se quisermos superar esta mazela social.

O discurso sobre a necessidade de expansão da produção de alimentos para a população brasileira, criado nos anos 1960/70 para respaldar as políticas de Estado orientadas para o aprimoramento das bases técnicas do campo e estimular a maior especialização do país na produção agrícola, mostrou-se falacioso diante dos resultados alcançados. A orientação para o mercado internacional que os circuitos produtivos contemplados pelo processo de modernização assumiram demonstra mesmo a extroversão da organização de parcela das atividades desenvolvidas no país. A constituição do círculo de cooperação de pesquisa para a moderna agricultura no Brasil pode ser interpretada como um processo, cujo objetivo foi o atendimento de demandas externas de mercado e não das necessidades e demandas da sociedade brasileira. Assim, o círculo de cooperação de pesquisa agrícola, ao mesmo tempo em que evidencia uma organização solidária do território, revela também, as contradições do uso desigual que se faz do território brasileiro.

A construção dos nexos territoriais corporativos promove assim a desarticulação interna do território nacional, na medida em que as atividades desenvolvidas pelas instituições integrantes das redes de pesquisa tornam-se alheias às carências da sociedade e, portanto, descoladas da solidariedade orgânica que, afinal, cimenta o território nacional.

O uso privado e privilegiado do conjunto de instituições públicas de pesquisa (empresas, universidades e institutos) é exemplo desse uso corporativo do território nacional que resulta no processo de fragmentação do território. Trata-se aqui, de um projeto tecno-político de modernização das atividades produtivas afinado às lógicas e aos interesses exclusivos do mercado de commodities, como é evidenciado em casos como o do agronegócio da soja.

A distância entre as finalidades do desenvolvimento tecnológico promovido pelo trabalho científico voltado ao campo e a necessidade de superação dos problemas sociais do país, tal como é o problema da fome, constitui-se num dos principais paradoxos brasileiros, tratando, por um lado, de viabilizar a inserção de subespaços nacionais à divisão interna e internacional do trabalho e, por outro lado, de inviabilizar a construção de uma nação politicamente forte, socialmente justa e coesa. 


\section{Referências bibliográficas}

BOUÇAS, C. Plantas transgênicas diminuem o uso de defensivos agrícolas. Valor Econômico, São Paulo, 9 jul. 2006a. Agronegócio, p. B-14.

. Área de soja transgênica deve crescer. Valor Econômico, São Paulo, 21 set. 2006b. Disponível em: <http://www.seagri.ba.gov.br/ noticias>. Acesso em: 24 set. 2006.

CARNEIRO, P.; PEREIRA, M. Território da desigualdade: pobreza, fome e concentração fundiária no Brasil Contemporâneo. Geografia, Rio Claro, v. 30, n. 2, p. 255-269, mai./ago. 2005.

CASTILLO, R.; TOLEDO JR,, R.; ANDRADE, J. Três dimensões da solidariedade em geografia. Experimental, São Paulo, ano 2, n. 3, p. 69-99, set. 1997.

CONTINI, E.; REIFSHNEIDER, F.; SAVIDAN, Y. Os donos do conhecimento no mundo. Ciência Hoje, São Paulo, v. 34, n. 34, p. 16-21, jan./fev. 2004.

DELGADO, G. Capital financeiro e agricultura no Brasil. São Paulo: Ícone/Editora Unicamp, 1985.

ELIAS, D. Globalização e agricultura: A região de Ribeirão Preto (SP). São Paulo: Edusp, 2003.

EMBRAPA. EMPRESA BRASILEIRA DE PESQUISA AGROPECUÁRIA. Centro Nacional de Pesquisa da Soja (CNPSO) - Embrapa Soja. Home Page Institucional. Londrina: Embrapa Soja, 2006. Disponível em: <http://www.cnpso.embrapa.br>. Acesso em: 4 out. em 2006.

. Tecnologias de produção da soja: Paraná 2005. Londrina: Embrapa Soja, 2004.

\section{EXAME. Guia Exame Especial} Agronegócio. São Paulo, ed., ago. 2005.
GRAZIANO DA SILVA, J. A modernização conservadora: estrutura agrária, fronteira agrícola e trabalhadores rurais no Brasil. Rio de Janeiro: Zahar, 1982.

KARPIK, L. Le Capitalism tecnologique. Sociologie du travail, Paris, v. 13, n. 1, p. 2-34, 1972.

MÜLLER, G. Complexo agroindustrial e modernização agrária. São Paulo: Hucitec/Educ, 1989.

NASCIMENTO JR., F. A Constituição do círculo de cooperação de pesquisa agrícola no Brasil: nova face do uso corporativo do território brasileiro no período técnico-científico-informacional. Dissertação (Mestrado em Geografia) - Instituto de Geociências e Ciências Exatas, Universidade Estadual Paulista, Rio Claro, 2007.

SANTOS, M. A Natureza do espaço: técnica e tempo, razão e emoção. São Paulo: Edusp, 2002.

- Materiais para o estudo da urbanização brasileira no período técnico-científico. Boletim Paulista de Geografia, São Paulo, v. 67, p. 516, 1989.

; SILVEIRA, M. L. O Brasil: território e sociedade no início do século XXI. Rio de Janeiro: Record, 2001.

SANTOS, T. Revolução científica-técnica e capitalismo contemporâneo. Petrópolis: Vozes, 1983.

SHIKI, S.; GRAZIANO DA SILVA, J.; ORTEGA, A. (Orgs). Agricultura, meio ambiente e sustentabilidade do cerrado brasileiro. Uberlândia: UFU/Embrapa/Unicamp, 1998. 